\title{
Attitudes of the Block Supervisors toward the Effect of Modern Agricultural Technologies on Environment
}

\author{
- a case study in Mymensingh District, Bangladesh-
}

\author{
Mohammad Jiaul Hoque (Bangladesh Agricultural University) \\ Koichi Usami (Yamaguchi University) \\ Abdul Halim (Bangladesh Agricultural University) \\ M. Abul Kashem (Bangladesh Agricultural University)
}

\section{Introduction}

Numerous technological advances have been made and all efforts are being made to intensively utilize those technologies. The major agricultural technologies so far are chemical fertilizer, pesticide and irrigation. The heavy reliance on such technologies and their application without consideration to the ecology have made a great concern for the environment. To minimize the adverse effects of modern agricultural technologies on human, domestic animals, other wild life and soil, there is a need to develop the attitude of those who are involved in handling and operating the agricultural technologies in contact with farmers.

In Bangladesh Block Supervisor (hereinafter, BS) is the lowest level extension worker of Department of Agricultural Extension, Ministry of Agriculture. The attitude of BSs is an important factor to his/her credibility as a professional worker of agricultural technologies. Unless the BSs have the favorable attitude towards the effect of modern agricultural technologies on environment as well as the knowledge on the subject matter, it would be impossible for them to motivate farmers to practice an environment-friendly farming and sustainable resource uses.

Thus, this study aims at seeking (1) the socio-economic profile of BSs, (2) the attitude of BSs towards the effect of modern agricultural technologies on environment and (3) the relationships of the attitudes of BSs with their socio-economic characteristics.

\section{Methodology}

The survey with questionnaire sheets was conducted in Mymensingh Distirct in Bangladesh. Out of 12 Upazilas in this District 3 Upazilas, namely Ishwargonj, Fulpur and Gouripure, were purposively selected for the study. Data were collected from 100 BSs out of the total 149 BSs assigned to the three Upazilas. The interview with the BSs was carefully scheduled and designed so that the data could be collected by the authors during September 10th to 25 th in 2001.

The attitude was measured by using five point Likert-type scales for 16 statements (10 positive effects and 6 negative effects). For instance, the respondent was asked to indicate hi $\mathrm{s} /$ her extent of agreement or disagreement with each of the 16 statements along the five point scale such as strongly agree, agree, no opinion, disagree and strongly disagree. The weight assigned to such responses was $4,3,2,1$ and 0 respectively for the positive statement and reverse scoring $0,1,2,3$ and 4 respectively for the negative statement. The attitude score of a respondent was determined by adding up such weighted points for all of the 16 statements.

For the analysis, firstly various statistical indicators such as range, mean, standard deviation (hereinafter, SD) and rank order were used to describe the nature of variance. Furthermore, so that the relationships of the attitudes of the BSs with their socio-economic characteristics could be found out the Pearson's Product Moment Correlation Coefficients were measured. 
Table 1 Socio-economic Profile of Block Supervisors (BSs)

\begin{tabular}{|c|c|c|c|c|}
\hline Item. & & Persons & Mean & $\mathrm{SD}$ \\
\hline \multirow{3}{*}{ Age } & young (31-39 years) & 29 & \multirow{3}{*}{42} & \multirow{3}{*}{5.1} \\
\hline & middle ( $40-47$ years) & 55 & & \\
\hline & old (above 47 years) & 16 & & \\
\hline \multirow{3}{*}{ Education } & SSC with agricultural diploma & 31 & \multirow{3}{*}{12} & \multirow{3}{*}{1.4} \\
\hline & HSC with agricultural diploma & 51 & & \\
\hline & Degree with agricultural diploma & 18 & & \\
\hline \multirow{3}{*}{$\begin{array}{l}\text { Tenure of } \\
\text { service }\end{array}$} & short $(10-16$ years $)$ & 18 & \multirow{3}{*}{20} & \multirow{3}{*}{4.5} \\
\hline & moderate (17-23 years) & 53 & & \\
\hline & long (above 23 years) & 29 & & \\
\hline \multirow{3}{*}{ Family Size } & small (2-4 members) & 42 & \multirow{3}{*}{5} & \multirow{3}{*}{1.7} \\
\hline & medium (5-7 members) & 52 & & \\
\hline & large (above 7 members) & 6 & & \\
\hline \multirow{3}{*}{ Annual income } & low (Tk. $40-80$ thousand) & 40 & \multirow{3}{*}{86} & \multirow{3}{*}{21.3} \\
\hline & medium (Tk. 81-100 thousand) & 38 & & \\
\hline & high (above 100 thousand) & 22 & & \\
\hline \multirow{3}{*}{$\begin{array}{l}\text { Training } \\
\text { experience }\end{array}$} & short duration (35-65 days) & 10 & \multirow{3}{*}{102} & \multirow{3}{*}{27.4} \\
\hline & medium duration (66-120 days) & 68 & & \\
\hline & long duration (above 120 days) & 22 & & \\
\hline \multirow{3}{*}{ Cosmopolitanism } & low (6-20 score) & 31 & \multirow{3}{*}{33} & \multirow{3}{*}{15.1} \\
\hline & medium (21-40 score) & 32 & & \\
\hline & high (above 40 score) & 37 & & \\
\hline \multirow{3}{*}{ Knowledge } & fair knowledge (16-20 score) & 23 & \multirow{3}{*}{21.7} & \multirow{3}{*}{1.4} \\
\hline & Good knowledge (21-22.5 score) & 46 & & \\
\hline & Very good knowledge (above 22.5 score) & 31 & & \\
\hline
\end{tabular}

Note) SD: standard deviation. US $\$ 1.00=$ Taka (Tk.) 58 in 2001.

Source: Field Survey, 2001

\section{Selection of Variables}

As to the variables for the analysis, reviewing such references as Islam and Kashem (1997), Rogers (1995) and Jha and Sarma (1973), the authors selected the 8 socioeconomic variables effective to the attitude of BS such as age, education level, family size, annual income, tenure of service, training experience, knowledge and cosmopolitanism. Herein, knowledge consists of chemical fertilizer, pesticide and irrigation. The cosmopolitanism is the degree or the frequency of communication with places outside his/her own working place. Needless to say, for the correlation analysis the 8 variables were independent variables while the attitude of BS is the dependent variable.

\section{Socio-economic Profile of Block Supervisors}

The characteristics of the sample BSs are shown in Table 1. Fifty five percent of the BSs were middle-aged, while only $16 \%$ old and $29 \%$ young. The majority (51\%) of the BSs were at the level of education of Secondary School Certificate with agricultural diploma, 31\% Higher School Certificate with agricultural diploma and the remaining $18 \%$ the graduation from college with agricultural diploma. More than half of the BSs had a medium family, followed by the small family (42\%). Forty percent of the BSs belonged to the low income class, followed by the medium income class (38\%). Fifty three percent of the BSs had a moderate tenure of service, while $18 \%$ and $29 \%$ were short tenure and longer tenure of service, respectively.

Sixty eight percent of the BSs had received a medium duration of training while only $10 \%$ for a short duration of training and $22 \%$ for a long duration of training. Forty six percent of the BSs had good knowledge, compared with $31 \%$ for very good knowledge and $23 \%$ for fair knowledge. Thirty seven percent of the BSs had a high cosmopolitanism, compared with $32 \%$ for a moderate cosmopolitanism and $31 \%$ for a low cosmopolitanism.

\section{Attitude to the Effect of Agricultural Technologies}

Attitude of each BS towards the effect of modern agricultural technologies on environment was scored, ranging from 0 (min.) to 64 (max.). In fact, the practical scores ranged from 40 to 63 with an average of 54 (standard deviation: 5.03) (Table 2). Thirty five percent of the BSs had a slightly favorable attitude, while 39\% a moderately favorable attitude. The highly favorable attitude was shown by only $26 \%$ of the 
Table 2 Block Supervisors' Attitude towards the Effect of Modern Agricultural Technologies on Environment

\begin{tabular}{lccc}
\hline Attitude & Persons & Mean & SD \\
\hline Slightly favorable attitude (40-51 score) & 35 & 18.9 & 1.76 \\
Moderately favorable attitude (51-58 score) & 39 & 21.0 & 1.96 \\
Highly favorable attitude (above 58) & 26 & 14.0 & 1.31 \\
Total (whole) & 100 & $(54.0)$ & $(5.05)$ \\
\hline
\end{tabular}

Note) SD: standard deviation.

Source: Field Survey, 2001. titude. As far as the coefficient was concerned, was comparatively effective the training experience rather than knowledge. Comparing with such significant characteristics, cosmopolitanism ( $\mathrm{r}=0.617,0.05 \%$ level) was significantly higher correlated with the attitude.
BSs.

\section{Relationship between Socio-economic Characteristics and Attitude}

Table 3 shows the results of the correlation analyses. As a whole, the significant characteristics were positively correlated with the attitude. Firstly, as to individual characteristics, age $(r=0.212,0.01 \%$ level $)$ and level of education $(r=0.433,0.05 \%$ level $)$ were significantly correlated with the attitude, although both of the extents were low. There was no significant correlation between the attitude and family size as well as annual income. From the aspect of practical capability, of BSs, not tenure of service but training experience $(\mathrm{r}=0.443,0.05 \%$ level $)$ was significantly correlated with the attitude. Besides, knowledge ( $r=0.253,0.01 \%$ level) itself was also significantly correlated with the at-

Table 3 Results of Correlation Analyses on Socioeconomic Characteristics of Block Supervisors and their Attitude towards the Effect of Modern Agricultural Technologies on Environment

\begin{tabular}{lc}
\hline Variable & Coefficient \\
\hline Age & $0.212 *$ \\
Level of education & $0.433 * *$ \\
Family size & -0.073 \\
Annual income & 0.131 \\
Tenure of service & 0.157 \\
Training experience & $0.443 * *$ \\
Knowledge & $0.253 *$ \\
Cosmopolitanism & $0.617 * *$ \\
\hline
\end{tabular}

Note) $*: 0.01 \%$ level of significant.

$* *: 0.05 \%$ level of significant.

Source: Field Survey, 2001.

\section{Conclusion}

Considering the significant variables such as age, level of education, training experience, knowledge and cosmopolitanism, age is explicitly related to the other 3 variables except level of education. Such 3 variables can be termed into one word, that is, intelligence of BSs. Education itself can be decisive to the resulting nature of training experience, knowledge and cosmopolitanism. For instance, the level of education is effective to an understanding of knowledge provided by training. Training itself enables to accumulate knowledge but knowledge is not necessary and sufficient condition. Comparing the coefficients of significant variables, however, what is more effective to the attitude is a capacity of cosmopolitanism rather than training experience so that knowledge can be transformed to recognition.

\section{References}

[1] E. M. Rogers, Diffusion of Innovation $4^{\text {th }}$, The Free Press, 1995.

[2] M. M. Islam and M. A. Kashem, "Attitude of Farmers towards the Use of Agrochemicals", Bangladesh Journal of Training and Development 10 (1\&2), pp.2328, 1997.

[3] P. N. Jha and B. M. Sharma, Impact of Institutional Training in Applied Nutrition on Village Level Workers, Indian Journal of Extension Education IX (3\&4), 1973. 